\title{
Perfis do Professorado da Rede Pública de São Paulo: A Interação entre Espaço, Regras Institucionais e Escolhas Individuais no Resultado de uma Política Pública*
}

\author{
Haroldo da Gama Torres \\ Sandra Gomes \\ Thais Pavez \\ Edgard Fusaro
}

\section{INTRODUÇÃO}

\begin{abstract}
A s principais análises contemporâneas da área de políticas públicas buscam compreender como as regras institucionais condicionam as ações dos agentes responsáveis por sua formulação e que impacto essa dinâmica acarreta no resultado dessas políticas (Immergut, 1998; Peters, 2005). Mais raramente, as escolhas dos agentes encarregados da implementação direta das políticas públicas - médicos, professores, policiais etc. - também são consideradas.
\end{abstract}

Uma exceção importante é dada pela literatura relativamente secundária da área de implementação de políticas públicas. Por exemplo, Lipsky (1983) e Weiss (1998) argumentam que os resultados das políticas públicas são afetados também pela discricionariedade desses funcionários que trabalham em contato com os usuários dos serviços públicos, também denominados "burocratas do nível da rua"1. Assumindo essa perspectiva, pretendemos argumentar, neste artigo, que as escolhas dos profissionais de educação-condicionadas por aspectos institucionais e pela organização socioespacial da cidade - influenciam significativamente a alocação de docentes nas escolas públicas de São Paulo, com possíveis impactos distributivos.

\footnotetext{
* Os autores agradecem a colaboração de Eric Daniele na realização desta pesquisa.

DADOS - Revista de Ciências Sociais, Rio de Janeiro, vol. 53, nº1, 2010, pp. 125 a 158.
} 
Estudos recentes ressaltam a complexidade analítica envolvida na interpretação dos resultados de políticas educacionais, dada a presença de diversos fatores que atuam simultaneamente no processo de implementação (Honig, 2006). Tal política se realiza na interação de diversos atores (professores, diretores, coordenadores, gestores públicos etc.) com as diversas instâncias institucionais (escolas, delegacias de ensino, secretarias municipais, secretarias estaduais etc.), que, ao longo do processo de implementação, tendem a transformar a intenção original dos formuladores da política em algo diverso do planejado originalmente. Nesse sentido, uma política desse tipo não pode ser entendida como "uma única realidade", isto é, um processo implementado homogeneamente em todas as escolas e em todas as regiões de uma cidade ou de um país. Embora a formulação e o desenho dessa política explicitem regras universais, passíveis de serem aplicadas regularmente em todas as escolas, observam-se frequentemente dinâmicas não esperadas, e até mesmo perversas, não necessariamente previsíveis durante o processo de formulação.

Quase sempre sem dialogar com a literatura de implementação de políticas, a literatura internacional da área de educação destaca com frequência o papel do professor no desempenho escolar dos alunos (Hanusheck, 1999), ressaltando aspectos relativamente inesperados, uma vez que nem sempre os professores com melhor formação acadêmica são os que produzem maior impacto educacional. Na literatura latino-americana, temas como o salário dos professores (Menezes Filho e Pazello, 2007), o nível de motivação dos professores (Soares, 2005), os modelos e as imagens que os professores constroem a respeito dos alunos pobres (Román, 2003) e suas escolhas quanto ao local de trabalho (Torres et alii, 2008) são considerados, analiticamente, fatores intervenientes mais ou menos relevantes ${ }^{2}$.

Entre os fatores mais discutidos na literatura, encontram-se o salário do professor, o grau de motivação, a experiência de ensino, o nível de escolaridade e a estabilidade no cargo. Por exemplo, em estudo recente sobre o ensino no Brasil, Menezes Filho e Pazello (2007) sugerem que a estabilidade e o tempo de carreira (mais de 15 anos) teriam impactos negativos na motivação ou no estímulo desses profissionais para dar aulas. Torres et alii (2008) identificam, por outro lado, efeitos perversos da "instabilidade" dos professores em regiões com alta concentração de pobreza na cidade de São Paulo em função da alta rotatividade dos quadros profissionais, comprometendo a continuação do projeto pe- 
dagógico dessas escolas. Portanto, não há um consenso absoluto sobre qual perfil de profissional tende a estar associado a um melhor desempenho educacional dos alunos, ainda que atributos como o nível e a qualidade da formação profissional e o grau de motivação apareçam como elementos importantes nos estudos desse tipo.

Neste artigo, o objetivo é identificar como os diferentes grupos de profissionais de ensino (anos iniciais do ensino fundamental) se distribuem do ponto de vista espacial e como tal distribuição é influenciada pelas regras institucionais existentes e pelas escolhas individuais dos professores. Vale notar que este estudo se baseia, em parte, na análise realizada por Figueiredo et alii (2005) para o município de São Paulo, que indicava que fatores institucionais induziam um acesso desigual a serviços públicos por parte da população com rendimentos mais baixos. Em relação aos serviços educacionais, os resultados evidenciaram, por exemplo, que o tempo de permanência da criança na escola era influenciado por fatores institucionais como tipo de dependência administrativa das escolas (estadual e municipal). Torres et alii (2008), por outro lado, observaram que regras de contratação e de alocação de professores influenciavam a oferta de serviços educacionais em distintos espaços da mesma cidade.

Pretendemos mostrar que os diversos tipos de professores não são igualmente distribuídos nas diferentes áreas da cidade e que isso tem consequências para as políticas educacionais. Levando em consideração o resultado de pesquisas anteriores, sobretudo no que diz respeito à possibilidade de encontrar padrões de oferta de serviços educacionais diferenciados segundo o tipo de rede, esta análise foi viabilizada a partir de um survey com 802 professores de escolas públicas de $1^{\underline{a}}$ a $4^{\underline{a}}$ série do ensino fundamental das redes municipal e estadual, realizado pelo Centro de Estudos da Metrópole, do Centro Brasileiro de Análise e Planejamento (CEM-Cebrap), em 2007.

Esta pesquisa foi elaborada a partir de uma amostra estratificada de professores de escolas públicas de $1^{\mathrm{a}}$ a $4^{\mathrm{a}}$ série do ensino público, segundo uma estratificação que considerou o tipo de rede (estadual/municipal), o rendimento escolar dos alunos por escola (baixa e alta pontuação no índice de rendimento da escola elaborado a partir do Saresp 2005 - Sistema de Avaliação de Rendimento Escolar do Estado de São Paulo - e da Prova Brasil 2004) e a localização espacial da escola. Foram entrevistados apenas dois professores por escola, distribuídos por tur- 
nos, sendo que critérios foram adotados para evitar a influência da direção da escola sobre a entrevista. A amostra final apresentou maior proporção de professores de escolas municipais em virtude da maior dificuldade de implementar a pesquisa na rede de ensino estadual, que mostrou mais resistência para outorgar o acesso dos pesquisadores às escolas. O questionário foi desenvolvido a partir de entrevistas em profundidade de grupos focais, realizados em etapas anteriores do projeto.

Além de uma análise univariada de dados desse survey, recorre-se aqui ao método grade of membership (GoM), que permite construir tipologias de professores com base nos atributos (autodeclarados) desse profissional. Consideramos também, na modelagem, dimensões institucionais relacionadas à lógica de operação do sistema de ensino. Finalmente, os perfis identificados foram espacializados a fim de observarmos até que ponto o professorado pode ser considerado homogêneo ou não em todos os locais da cidade de São Paulo.

Nossos resultados mostram que, a despeito das regras "racionais-legais" adotadas pelo sistema educacional, tais como a impessoalidade e o caráter técnico da seleção (válidas de forma universal para todos os professores), é possível observar uma variação considerável no perfil dos professores que lecionam nas diferentes regiões da cidade e, simultaneamente, revelam um quadro bastante complexo do sistema educacional.

Em um estudo baseado em métodos qualitativos, Torres et alii (2008) propunham o argumento de que as regras institucionais acabavam por gerar, ainda que de forma não intencional, incentivos para que uma parte significativa dos professores optasse por atuar em escolas mais centrais ao longo da evolução de sua carreira. Um dos discursos mais frequentes desses profissionais era que, em algumas escolas localizadas em áreas com alta concentração de pobreza, a rotatividade do corpo docente e dos cargos de direção era mais frequente do que em escolas localizadas nas áreas mais centrais e ricas da cidade. Os fatores explicativos associados a tal comportamento eram a distância e o tempo para chegar à escola, o menor grau de organização da comunidade local e o perfil dos alunos (menor escolaridade dos pais ou "famílias desestruturadas", nas palavras de alguns profissionais). Como consequência, parte considerável dos entrevistados declarava ter como meta mudar para escolas mais centrais ao longo da carreira. A presente 
análise retoma esses argumentos a partir de dados quantitativos, buscando também mostrar que parte dos professores que trabalham em escolas localizadas em áreas com alta concentração de pobreza da cidade tende a estar menos preparada ou menos motivada com o trabalho e mudaria dessas escolas se tivesse oportunidade.

O artigo está dividido em três partes, além desta introdução e da conclusão. Na primeira parte, discutimos a heterogeneidade de resultados da política educacional e sua relação com o processo de implementação. Na segunda, realizamos uma análise da distribuição espacial da oferta de serviços do ensino fundamental das redes estadual e municipal. Finalmente, apresentamos uma tipologia de professores da rede de ensino público municipal e estadual, e discutimos o significado da distribuição desses perfis segundo a localização das escolas em que tais professores lecionam.

\section{DEBATE SOBRE DESIGUALDADE, ESPAÇO E IMPLEMENTAÇÃO DE POLÍTICAS EDUCACIONAIS}

Apesar do forte aumento da oferta de serviços educacionais no Brasile do avanço no sentido de sua universalização nas principais regiões metropolitanas, persistem importantes desigualdades educacionais no interior dos sistemas públicos brasileiro e paulistano (Barros et alii, 2001; Torres, Gomes e Ferreira, 2005) ${ }^{3}$. Vale notar que a desigualdade na oferta de serviços entre áreas com alta concentração de pobres e áreas tipicamente de renda média ou alta, caracterizada, por exemplo, a partir de indicadores como os relacionados à qualidade dos equipamentos educacionais e ao perfil do corpo docente, é altamente perturbadora para uma política universal que busca, em última instância, contribuir para a redução das desigualdades sociais a longo prazo.

Diferentes estudos sobre áreas metropolitanas sugerem que a chamada segregação residencial acarreta consequências do ponto de vista da reprodução da pobreza e da desigualdade até mesmo no interior da escola (Durlauf, 2001; Wilson, 2008). É mais raro observar, porém, na área educacional, análises que investiguem a natureza dos serviços públicos efetivamente presentes nas áreas com alta concentração de pobres e políticas que condicionem a oferta desses serviços. A rigor, não pretendemos tratar aqui a segregação como uma variável explicativa da desigualdade educacional. Ao contrário, buscamos observar a heterogeneidade espacial que se forma no interior de um sistema educacional que deveria, em tese, ser homogêneo espacialmente. Nesse sentido, 
queremos observar até que ponto o próprio sistema educacional, dadas suas características, contribuiria ou não para a reprodução e a perpetuação de desigualdades já existentes.

Entendemos que os processos de implementação de políticas - por meio das escolhas dos profissionais que as executam localmente ou por meio das estratégias espaciais eventualmente existentes por parte dos gestores das políticas - podem contribuir para a diferenciação territorial da oferta das políticas sociais criando, reforçando ou combatendo processos de segregação. Vale lembrar que qualquer política social, quando implementada no espaço metropolitano, implica, por parte dos gestores públicos, decisões mais ou menos arbitrárias sobre onde investir, onde implementar equipamentos sociais, que profissionais alocar em cada área etc. Tais decisões podem ter, em muitos casos, consequências distributivas, sobretudo quando a distribuição dos grupos sociais no espaço for muito heterogênea ${ }^{4}$.

A presente análise destaca, assim, o caráter não determinístico da política educacional, isto é, entendendo o resultado dessa política não apenas como fruto da lógica dos formuladores mas também como condicionada pelo contexto em que é implementada e pelas escolhas dos profissionais do "nível da rua" (Hill, 1982; Barret, 2004). Em outras palavras, acreditamos que os resultados das ações públicas são também afetados pelas interações entre os diferentes níveis governamentais e administrativos, bem como pela escolha discricionária de quadros técnicos e de trabalhadores de linha de frente e/ ou burocratas, que implementam tal política no dia a dia.

Em síntese, como consequência dos processos de formulação e implementação, a configuração espacial de uma dada política pública pode assumir diferentes formatos, seja no que tange à distribuição de investimentos em infraestrutura e equipamentos, seja no que diz respeito a decisões sobre a alocação e a disponibilização de serviços e de recursos humanos. Todos esses elementos podem ter consequências distributivas e induzem a variações na qualidade e na diversidade de serviços oferecidos em nível local.

\section{EVIDÊNCIAS SOBRE A POLÍTICA DE ENSINO FUNDAMENTAL EM SÃO PAULO}

Uma primeira evidência importante a respeito da heterogeneidade da distribuição dos docentes diz respeito à disposição espacial dos pro- 
fessores efetivos e não efetivos da rede estadual nas diferentes diretorias de ensino (Mapa 1). Podemos observar a marcante presença de profissionais não efetivos nas diretorias de ensino mais distantes do centro e do vetor centro/sul da cidade de São Paulo, como as diretorias Sul 2 e 3, e Leste 2 e 3. Os profissionais não efetivos são aqueles contratados em regime precário, sendo que parte deles fez concurso público e não foi aprovada. Como o Estado de São Paulo passou um longo período sem concurso, os professores concursados tendem a migrar paulatinamente para as "melhores escolas" - boa parte delas localizada em áreas centrais, que também são áreas com baixa concentração de pobreza, enquanto novos professores temporários são alocados em esco-

\section{Mapa 1}

Distribuição de professores efetivos e não efetivos da rede estadual de São Paulo, segundo diretorias de ensino (2006)

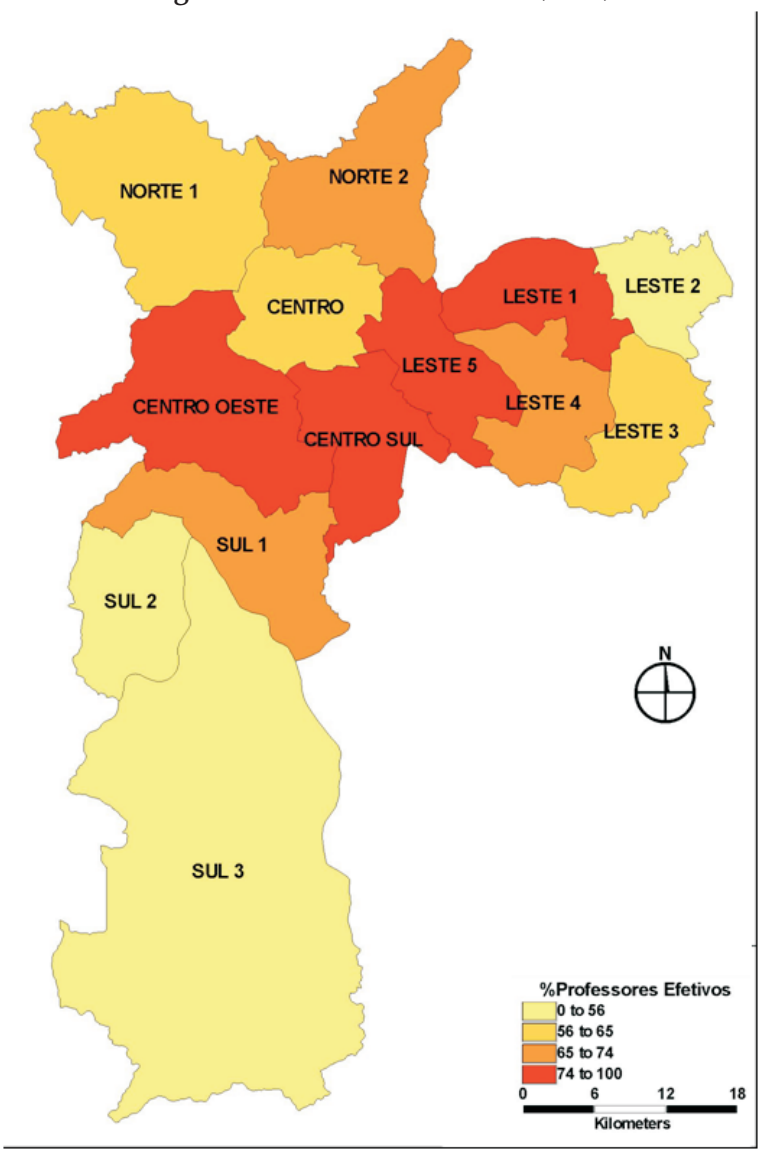

Fonte: Secretaria Estadual de Educação. 
las mais distantes do centro. Vale notar que as escolas das áreas periféricas, e também mais pobres, têm os alunos com o pior acesso à pré-escola, além daqueles oriundos de famílias de menor nível educacional.

Os dados obtidos a partir do survey de professores da rede de ensino pública de São Paulo, em 2007, indicam também maior presença de professores temporários em escolas estaduais do que em escolas municipais (Tabela 1). Podemos observar que boa parte dos professores da rede estadual declara não fazer parte do quadro permanente da escola. Como vimos no Mapa 1, a proporção de não efetivos é mais significativa em áreas de alta concentração de pobreza, na periferia urbana. No caso das escolas municipais, porém, a proporção de não efetivos é muito menor. Trata-se provavelmente de um sistema que faz concursos com muito mais frequência, tornando a categoria "não efetivos" um fenômeno relativamente residual.

\section{Tabela 1}

Proporção de professores não efetivos em escolas públicas de $1^{\underline{a}}$ a $4^{\underline{a}}$ série do ensino fundamental, segundo rede de ensino

Município de São Paulo (2007)

\begin{tabular}{l|c}
\hline Tipo de rede de ensino & Proporção de não efetivos \\
\hline Municipal & $4 \%$ \\
Estadual & $46 \%$ \\
Todas as escolas & $20 \%$ \\
\hline
\end{tabular}

Fonte: CEM-Cebrap (2007). Survey de professores do ensino público em São Paulo.

Notas: 1. Os dados são relativos à autodeclaração dos professores quanto à sua situação ocupacional. 2. Dados não ponderados.

Não temos elementos suficientes para interpretar o significado da elevadíssima proporção de não efetivos em escolas estaduais. É provável que tal fenômeno esteja relacionado aos custos de manutenção dos professores concursados, inclusive em função dos impactos previdenciários associados. Outra hipótese diz respeito a uma estratégia não explícita dos governos estaduais de enfraquecimento das organizações sindicais, que são muito atuantes nessa categoria. Em qualquer hipótese, a grande presença de professores em situação funcional mais instável e sua maior concentração em áreas pobres (como indicado no Mapa 1) sugerem claramente que o sistema estadual é heterogêneo do ponto de vista espacial. Quando considerados outros elementos, como o tempo de permanência na escola, a formação acadêmica dos professores, o 
absenteísmo destes e o tempo de deslocamento do professor até a escola, podemos observar que existem diferenciais declarados entre áreas pobres e não pobres presentes para todas as variáveis consideradas em escolas estaduais e municipais (Tabela 2). As distinções entre áreas pobres e não pobres foram definidas aqui a partir de uma análise do tipo Moran Local para a escolaridade média dos chefes de domicílio dos setores censitários do Censo de $2000^{5}$.

Tabela 2

Indicadores do perfil de professores em escolas públicas de $1^{\underline{a}}$ a $4^{\underline{a}}$ série do ensino fundamental, segundo tipo de região

Município de São Paulo (2007)

\begin{tabular}{|c|c|c|}
\hline $\begin{array}{l}\text { Proporção de professores que se declaram segundo } \\
\text { os atributos abaixo: }\end{array}$ & $\begin{array}{c}\text { Áreas } \\
\text { pobres }\end{array}$ & $\begin{array}{c}\text { Áreas intermediárias } \\
\text { e ricas }\end{array}$ \\
\hline \multicolumn{3}{|l|}{ Escolas municipais } \\
\hline Permanência de até 4 horas por dia & $85 \%$ & $92 \%$ \\
\hline Professores com educação secundária & $4 \%$ & $2 \%$ \\
\hline Baixa pontuação no último concurso para professor & $6 \%$ & $1 \%$ \\
\hline Dez dias ou mais de falta no último ano* & $67 \%$ & $65 \%$ \\
\hline $\begin{array}{l}\text { Mais de } 30 \text { minutos de tempo de deslocamento até a } \\
\text { escola }\end{array}$ & $21 \%$ & $10 \%$ \\
\hline \multicolumn{3}{|l|}{ Escolas estaduais } \\
\hline Permanência de até 4 horas por dia & $15 \%$ & $8 \%$ \\
\hline Professores com educação secundária & $29 \%$ & $18 \%$ \\
\hline Baixa pontuação no último concurso para professor & $14 \%$ & $10 \%$ \\
\hline Dez dias ou mais de falta no último ano* & $32 \%$ & $12 \%$ \\
\hline $\begin{array}{l}\text { Mais de } 30 \text { minutos de tempo de deslocamento até a } \\
\text { escola }\end{array}$ & $26 \%$ & $14 \%$ \\
\hline \multicolumn{3}{|l|}{ Todas as escolas } \\
\hline Permanência de até 4 horas por dia & $48 \%$ & $28 \%$ \\
\hline Professores com educação secundária & $14 \%$ & $8 \%$ \\
\hline Baixa pontuação no último concurso para professor & $9 \%$ & $4 \%$ \\
\hline Dez dias ou mais de falta no último ano* & $57 \%$ & $49 \%$ \\
\hline $\begin{array}{l}\text { Mais de } 30 \text { minutos de tempo de deslocamento até a } \\
\text { escola }\end{array}$ & $23 \%$ & $11 \%$ \\
\hline
\end{tabular}

Fonte: CEM-Cebrap (2007). Survey de professores do ensino público em São Paulo.

* Uma elevada proporção de entrevistados não respondeu a essa pergunta. Excluímos aqui os missing values.

Notas: 1. Os dados são relativos à autodeclaração dos professores quanto à sua situação ocupacional. 2. Dados não ponderados. 
De fato, os professores que trabalham em áreas com alta concentração de pobreza declaram ministrar em média menos de quatro horas de aula por dia (o que é quase universal nas escolas municipais), possuir uma qualificação mais baixa, faltar com mais frequência e investir mais tempo no deslocamento até a escola. Embora alguns desses dados possam estar subestimados em função da autodeclaração (sobretudo no que diz respeito à informação sobre faltas e à classificação no último concurso para professor), podemos observar que as escolas de áreas mais pobres se encontram em situação menos favorável para todos os indicadores selecionados.

A rigor, mesmo que alguns dos diferenciais observados pareçam relativamente baixos, observa-se aqui uma espécie de efeito cumulativo: a existência de escolas e de áreas que reúnem um número maior de professores que agregam, simultaneamente, muitos atributos "negativos" do ponto de vista educacional e, ao mesmo tempo, localizadas em regiões mais pobres, isto é, recebendo maior frequência de alunos oriundos de famílias menos escolarizadas. Em outras palavras, as áreas mais pobres recebem as escolas com maior proporção de professores com características desfavoráveis. Certamente, parece se tratar de uma forma não planejada de discriminação negativa.

Quando associamos tais dados aos da oferta de equipamentos educacionais (conforme declarados pelos professores), as escolas de áreas pobres se sobressaem novamente de modo negativo (Tabela 3). Vale notar que, mesmo quando os equipamentos existem, não necessaria-

Tabela 3

Proporção de escolas públicas de $1^{\underline{a}}$ a $4^{\underline{a}}$ série do ensino fundamental, com equipamentos educacionais efetivamente utilizados, segundo tipo de região Município de São Paulo (2007)

\begin{tabular}{l|c|c}
\hline Equipamentos efetivamente utilizados & Áreas pobres & Áreas intermediárias e ricas \\
\hline Biblioteca & $58 \%$ & $65 \%$ \\
Laboratório de informática & $59 \%$ & $71 \%$ \\
Quadra esportiva & $78 \%$ & $93 \%$ \\
Brinquedoteca & $5 \%$ & $11 \%$ \\
Equipamento de vídeo & $87 \%$ & $92 \%$ \\
Sala de leitura & $74 \%$ & $81 \%$ \\
\hline
\end{tabular}

Fonte: CEM-Cebrap (2007). Survey de professores do ensino público em São Paulo.

Notas: 1. Os dados são relativos à autodeclaração dos professores quanto à sua situação ocupacional. 2. Dados não ponderados. 
mente são usados pelos professores ou pelos alunos para fins educacionais. Como verificamos no relato de professoras e de diretoras entrevistadas em pesquisa qualitativa, esses equipamentos muitas vezes ficam trancados por questão de segurança, restringindo, com isso, o uso por parte dos alunos. Mais uma vez, embora os diferenciais não sejam muito altos, as escolas de áreas mais pobres são mais mal classificadas, segundo todos os indicadores considerados.

Assim, o conjunto de dados apresentados aqui sugere que a distribuição de professores não efetivos, a ocorrência de professores com características desfavoráveis e a ausência de equipamentos educacionais em uso efetivo são desproporcionalmente concentradas nas escolas localizadas nas regiões mais pobres da cidade. Tais carências se somam às desvantagens individuais derivadas da pior condição socioeconômica, como a escolaridade da mãe, a cor da pele, os problemas do local de moradia etc. Tudo isso contribui, provavelmente, para tornar as desigualdades sociais existentes em São Paulo mais persistentes ao longo do tempo (Tilly, 1999).

Contudo, vale notar que tais resultados são derivados de uma análise univariada. A fim de avançar na compreensão sobre como esses aspectos se combinam na realidade, criamos tipologias de professores da rede pública com base em modelos multivariados, buscando identificar melhor um universo que é provavelmente muito mais complexo e diversificado do que o apresentado até o momento. Detalhamos os resultados na seção seguinte.

\section{ESPAÇO E PERFIL DO PROFESSOR DA REDE PÚBLICA}

Em função do constatado na seção anterior, isto é, de que existem variações importantes no tipo de profissional de ensino segundo o tipo da região em que se localiza a escola, buscamos agora construir uma tipologia de profissionais do ensino público fundamental. A análise está baseada na metodologia de grau de associação, ou GoM (grade of membership). Tal metodologia é da família de modelos estatísticos fuzzy, que é utilizada na interpretação de dados heterogêneos, vagos ou difusos. Essa abordagem é particularmente apropriada para representar contínuos, propiciando melhores resultados do que os modelos que trabalham com categorias discretas e marcadamente distintas, como é o caso de regressões lineares ou logísticas. Estatísticas fuzzy são também recomendadas para situações em que as características definidoras do 
objeto de análise têm várias dimensões e são, portanto, representadas por diversas variáveis (Sydenstricker-Neto, 2004).

O GoM foi desenvolvido por Woodbury e Manton (1982) e originalmente aplicado a análises de sistemas de diagnóstico médico (Manton, Woodbury e Tolley, 1994; Woodbury, Clive e Garson Jr., 1978; Woodbury e Manton, 1982). Com o decorrer dos anos, sua aplicação atingiu outras áreas do conhecimento, como a psicologia, a demografia e o sensoriamento remoto (Berkman, Singer e Manton, 1989; Davidson et alii, 1988; Lamb, 1996; Piccinelli et alii, 1999; Portrait, Lindeboom e Deeg, 2001; Talbot et alii, 1999). No Brasil, tem sido utilizado na demografia e na sociologia para, por exemplo, estudos sobre o mercado de trabalho (Guimarães e Melo, 2008). Para mais detalhes sobre a metodologia, ver o Anexo 1.

As variáveis consideradas na análise foram agrupadas em três grupos principais:

1) atributos sociodemográficos: escolaridade, renda, cor/raça, faixa etária e estado civil;

2) atributos profissionais gerais: carga horária semanal em todos os trabalhos, trabalho adicional em outra escola, envolvimento com o Sindicato dos Professores, tempo de trabalho como professor da rede pública, tipo de vínculo de trabalho e classificação no último concurso público para professor;

3) atributos profissionais relacionados à escola pesquisada: tempo de trabalho na atual escola, tempo de permanência em sala de aula, motivação quanto ao trabalho na atual escola, desejo de transferência para outra escola, número de faltas em 2006, tempo de deslocamento até a escola, principal meio de transporte utilizado para ir ao trabalho e tipo de sistema escolar.

Os resultados encontrados nos permitem identificar três perfis puros de professores ${ }^{6}$. Em primeiro lugar, destaca-se o perfil 1 (Quadro 1). Trata-se de um professor com um nível de formação mais baixo do que os demais e um vínculo empregatício mais fluido (não concursado). Apesar de a maioria desses profissionais ter curso superior completo, é maior a presença de professores que concluíram apenas o ensino médio, com ou sem magistério. São profissionais que não fizeram concursos para o magistério ou que, quando o fizeram, alcançaram baixa pontuação. A maioria está em início de carreira, trabalha há até cinco anos como professor da rede pública e, dados o grau de instabilidade fun- 
Perfis do Professorado da Rede Pública de São Paulo: A Interação entre Espaço...

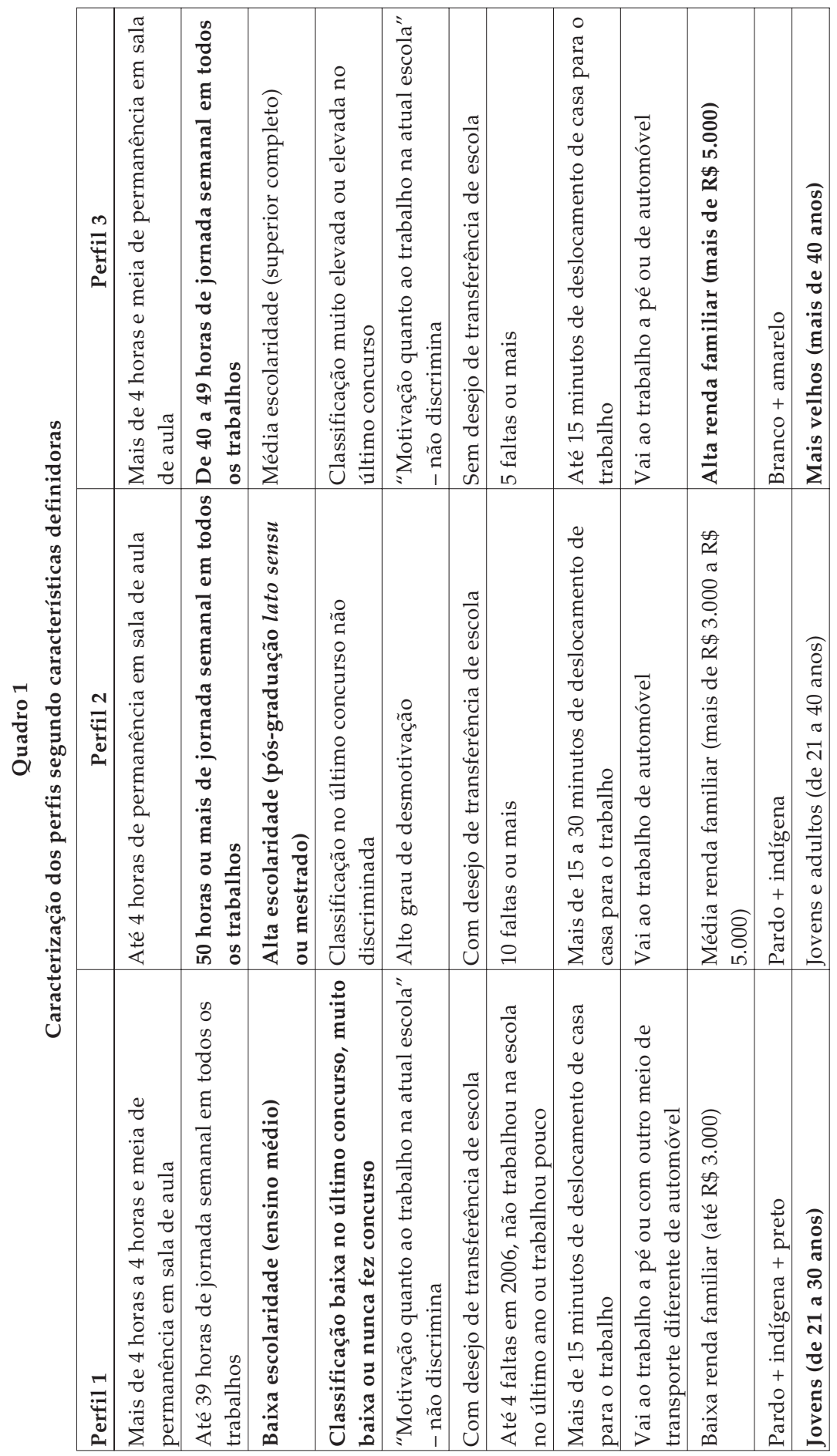

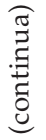




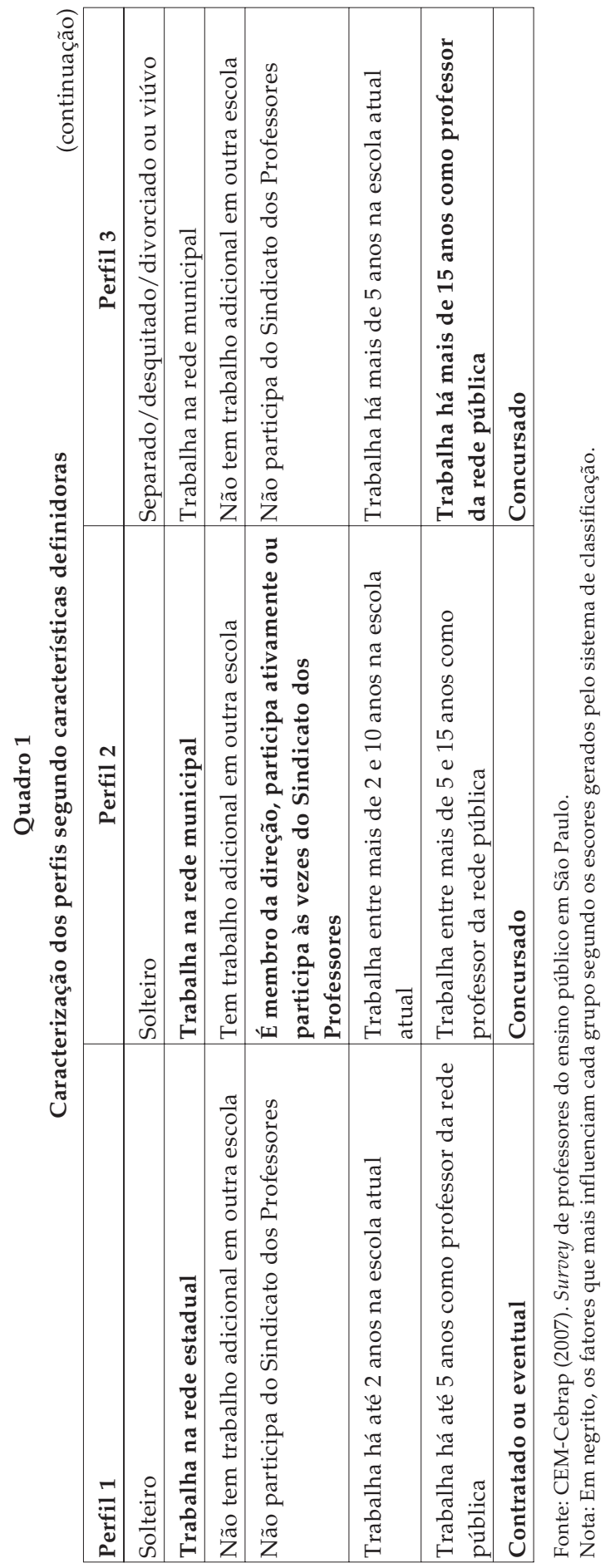


cional e a baixa pontuação em concursos e provas, possivelmente apresenta alta rotatividade nas escolas em que atua: a maior parte estava, no máximo, havia dois anos na escola atual.

Em termos de características socioeconômicas, esse grupo de professores vive com uma renda familiar baixa, é jovem e apresenta maior proporção de solteiros e de pessoas que se classificam como parda, preta ou indígena. Com relação ao trabalho, tendem a permanecer em sala de aula mais de 4 horas e meia por classe, cumprem carga horária semanal de até 39 horas em todos os trabalhos e tendem a não trabalhar em outra escola. Trata-se provavelmente de profissionais iniciantes, não plenamente formados e que, portanto, entram no sistema educacional como professores contratados ou eventuais. Esse tipo de profissional é mais facilmente encontrado na rede estadual de educação. Em termos quantitativos, o perfil 1 soma cerca de $17 \%$ dos professores da rede pública.

Em segundo lugar, chama também a atenção os professores pertencentes ao perfil 2. Têm como características predominantes alta qualificação profissional, jornada de trabalho bastante intensa e participação nas atividades promovidas pelo sindicato da categoria. Diferentemente do perfil 1, quase a totalidade dos professores do perfil 2 era concursada e mais da metade declarou ter tido uma pontuação alta ou muito alta no último concurso. Nesse perfil, estão os professores de mais alta qualificação profissional entre todos os perfis puros observados: praticamente todos têm o curso superior completo e cerca de um quarto possui pós-graduação. São profissionais com algum tempo na carreira do magistério (mais de 5 a 15 anos como professor da rede pública) e apresentando mais tempo de permanência na escola em que atuam (entre mais de 2 e 10 anos).

Em termos de características socioeconômicas, o perfil 2 mostra um profissional que vive com uma renda familiar intermediária (de mais de $\mathrm{R} \$ 3.000$ a $\mathrm{R} \$ 5.000$ ) e com idade intermediária (com forte presença de pessoas entre 30 e 40 anos, mas também com jovens com mais de 21 anos). Em termos de jornada de trabalho, a principal característica que diferencia os professores desse perfil é a quantidade de horas trabalhadas na semana: mais de $90 \%$ deles trabalhavam 50 horas ou mais, sendo que, na maior parte dos casos, essa jornada adicional era realizada em uma segunda escola ( $87 \%$ ). Com relação ao tempo de deslocamento de casa para a escola, boa parte dos professores desse perfil leva de 
mais de 15 a 30 minutos. Contudo, o meio de transporte mais utilizado, no caso desse perfil, é o automóvel (próprio ou carona), sugerindo que esses professores tendem a residir longe do local de trabalho.

A combinação da longa jornada de trabalho semanal com o elevado tempo de deslocamento de casa para o trabalho pode explicar a presença considerável de professores nesse perfil que se declaram desmotivados. É também provável que a elevada carga de trabalho e os problemas de deslocamento para a escola induzam ao maior absenteísmo observado nesse grupo. Existe também a possibilidade de que parte deles se considere sobrequalificada (over-qualified) para a posição que ocupam, induzindo problemas de adaptação.

Com relação à rede de ensino em que esses profissionais atuam, mais de $75 \%$ estão na rede municipal. Associado a esse ponto, esses profissionais estão mais presentes em escolas localizadas em áreas da cidade com alta concentração de pobreza (cerca de 73\%), já que há maior presença de escolas municipais nessas regiões. O curioso desse resultadoé que, ao contrário do apresentado na análise univariada, há profissionais do magistério altamente qualificados atuando em escolas localizadas em áreas com alta concentração de pobreza, ainda que isso seja em boa parte explicado pela maior presença de escolas municipais nessas áreas. Isso não quer dizer que as escolas localizadas em áreas de alta concentração de pobreza tenham sempre professores mais qualificados e estáveis, como a análise univariada evidenciou. Em termos quantitativos, o perfil puro 2 correspondia a aproximadamente $14 \%$ do professorado da rede pública.

Os professores de perfil 3 têm como principais características uma longa carreira como professor concursado da rede pública (mais de $96 \%$ trabalhavam havia pelo menos 15 anos) e, como esperado, uma idade mais elevada. A maioria tem mais de 40 anos de idade. Cerca de $95 \%$ tinha o superior completo, ou seja, uma boa qualificação, porém a presença de profissionais com pós-graduação nesse perfil é baixa em comparação aos professores do perfil 2.

Com relação às características socioeconômicas, esse grupo tem, em média, a renda familiar mais alta entre todos os perfis (acima de $\mathrm{R} \$$ 5.000), concentra uma proporção elevada de pessoas separadas, divorciadas e viúvas e de indivíduos que se classificam como brancos ou amarelos. Com relação à jornada de trabalho, esse perfil de professores 
tende a trabalhar entre 40 e 49 horas semanais, estando mais frequentemente fixado em uma única escola.

Os professores desse perfil também passam mais tempo em sala de aula com os alunos: mais de 4 horas e meia por dia. Assim como os professores de perfil 1, esses profissionais também se caracterizam por não participar das atividades do sindicato ou por não acompanhá-las. Em termos de tempo de deslocamento, os professores de perfil 3 são os que levam menos tempo de casa para a escola onde atuam: no máximo 15 minutos. Além disso, o principal meio de transporte é o automóvel ou a pé, sugerindo que boa parte desses profissionais reside bem próximo às escolas em que lecionam. Talvez essa seja uma importante razão que explique por que apenas $2 \%$ dos professores desse perfil trocariam de escola se tivessem a oportunidade de fazê-lo.

É possível que boa parte desses professores tenha se localizado no início de suas carreiras em escolas de áreas com maior concentração de pobreza. Além disso, é possível que, ao longo da progressão da carreira desse professor, ele tenha tendido a se transferir para as áreas não pobres. Se tomarmos como elemento adicional o fato de esse profissional ter tido uma elevada classificação no último concurso, aliado às regras de transferência e de escolha de escolas - que permitem aos mais bem classificados escolher primeiro as escolas onde vão lecionar-, podemos notar que esses profissionais, os mais experientes do ponto de vista de anos na carreira, acabam tendo incentivos para atuar em escolas de áreas mais ricas, localizadas nas áreas centrais. As razões para isso não se restringem apenas às próprias regras de incentivo do sistema de classificação dos professores, mas também ao menor tempo de deslocamento até suas residências. Com relação à rede de ensino predominante nesse perfil do professorado, novamente aparece a rede municipal: cerca de $91 \%$. Em termos quantitativos, o perfil puro 3 corresponde a cerca de $9 \%$ do total do professorado da rede pública.

Esses três tipos puros abrangem apenas $41 \%$ do universo dos profissionais entrevistados. Para os 59\% dos professores entrevistados, a técnica empregada constrói combinações dos tipos puros identificados inicialmente, permitindo, então, a construção de intermediários ou mistos, isto é, que apresentam elementos combinados de dois ou três tipos puros ${ }^{7}$.

Para melhor compreender tal tipologia, apresentamos, no Gráfico 1 a seguir, a distribuição de todos os tipos observados segundo o sistema 


\section{Gráfico 1}

Perfis de professores de $1^{\mathrm{a}}$ a $4^{\mathrm{a}}$ série do ensino fundamental público, segundo tipo de rede e área da cidade de São Paulo (2007)

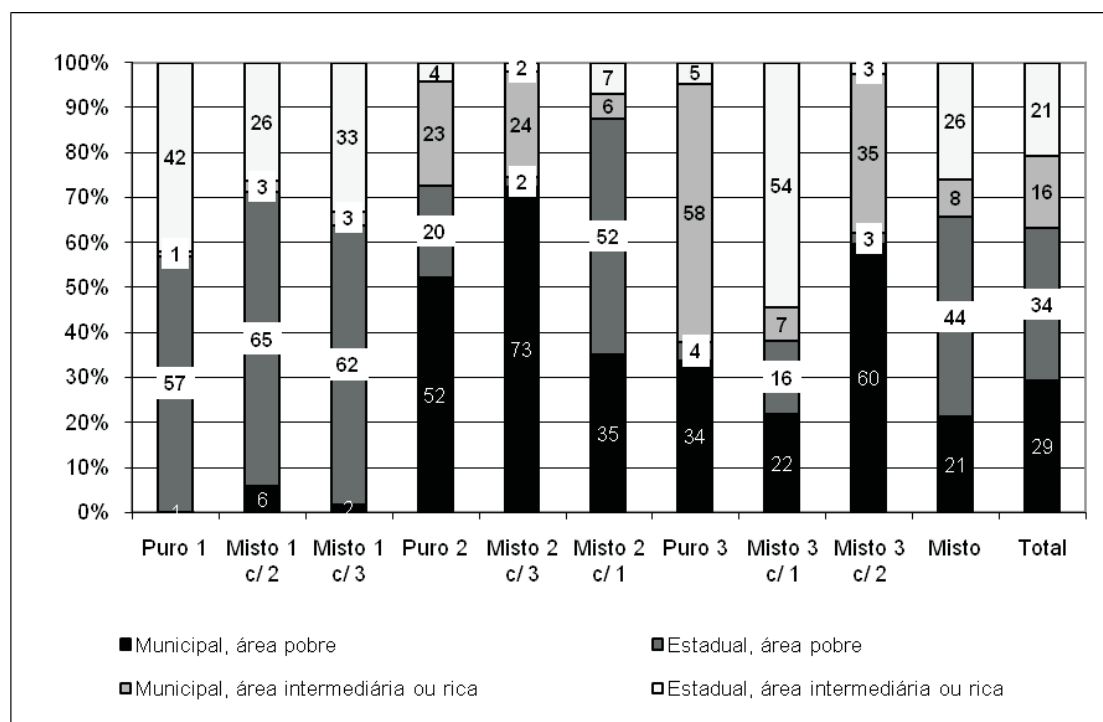

Fonte: CEM-Cebrap (2007). Survey de professores do ensino público em São Paulo.

educacional (estadual ou municipal) e a localização da escola em que o tipo de professor em questão leciona no espaço urbano (área com concentração de pobreza ou áreas intermediárias e ricas).

Podemos observar uma clara distinção entre os perfis em termos espaciais e em termos de tipo de sistema de ensino (estadual ou municipal). O perfil puro 1 e as combinações nas quais predominam esse perfil (misto 1 com 2 e misto 1 com 3$)^{8}$ são quase inteiramente constituídos de escolas estaduais. Isso é de se esperar, uma vez que o principal atributo dos profissionais de tipo 1 é a maior instabilidade quanto ao vínculo empregatício, isto é, não são professores efetivos. Como quase todos os não efetivos pesquisados estão na rede estadual, é natural que esse grupo se concentre nesse sistema. Em termos espaciais, o tipo puro $1 \mathrm{e}$ suas combinações se concentram um pouco mais fortemente nas áreas com concentração de pobres, embora exista uma parcela importante de professores com esse perfil em áreas intermediárias e ricas, conforme a análise univariada já indicava.

O perfil puro 2 e as combinações em que predominam o perfil 2 ocorrem com mais frequência em escolas municipais, exceto pelo grupo 
misto de 2 com $1^{9}$. Trata-se daquele grupo de professores que tem como principais características a melhor qualificação, o excesso de carga horária e maior participação em atividades sindicais. Em termos espaciais, eles tendem a estar mais concentrados em áreas pobres, embora estejam também presentes, em alguma proporção, em áreas mais ricas.

Em outras palavras, as áreas pobres parecem agrupar predominantemente dois grandes perfis de profissionais, que merecem ser tratados distintamente, conforme o tipo de sistema educacional:

a) Nas escolas estaduais de áreas mais pobres, é comum a presença do perfil puro 1 e dos tipos com predominância do perfil 1. Isso ocorre porque, como se trata de um sistema que ficou muitos anos sem realizar concurso público, o processo de substituição de profissionais e de ampliação territorial da rede se dá pela incorporação de professores não efetivos e em caráter mais precário. Decorre daí a maior frequência de professores mais jovens, com menor escolaridade e pior pontuação nos concursos públicos (quando os fizeram) que trabalham sobretudo em escolas em áreas de alta concentração de pobreza.

b) Nas escolas municipais de áreas mais pobres, é mais comum a presença de profissionais do perfil 2 e dos tipos mistos com predominância do perfil 2. Trata-se de um sistema que realizou concursos públicos com frequência nos últimos anos. Decorrem daí a menor presença de não efetivos e a maior presença de profissionais com melhor qualificação. Contudo, surpreendentemente, são também aqueles agentes com carga horária mais elevada, maior tempo de deslocamento para o trabalho e maior proporção de pessoas desmotivadas.

Não temos dados objetivos para avaliar qual desses tipos de condição educacional nas áreas mais pobres acarreta melhor ou pior nível de desempenho escolar. Cada condição, a seu modo, revela problemas graves, não necessariamente solucionáveis pelo recurso ao concurso público. No sistema estadual, a ausência de concurso implica a concentração, sobretudo nas áreas mais pobres, de uma elevada proporção de profissionais menos qualificados. No sistema municipal, os profissionais de áreas com alta concentração de pobreza, embora mais qualificados, são aqueles que parecem estar mais estressados em consequência do excesso de jornada de trabalho, do tempo de deslocamento até a escola e, possivelmente, por causa das dificuldades associadas ao 
ensino nessas regiões, embora não tenhamos aqui elementos relevantes para avaliar esse último aspecto.

Embora exista uma parcela expressiva dos perfis 1 e 2 e dos tipos mistos associados a esses perfis em áreas não pobres (intermediárias ou ricas), essa presença não caracteriza o principal elemento distintivo desses locais. Os únicos grupos predominantemente concentrados em áreas não pobres são os perfis puro 3 e misto $3 \operatorname{com~} 1^{10}$. Vale notar que o perfil puro 3 tem como principais atributos a presença de professores concursados, com carga horária intermediária, idade mais elevada, boa classificação em concursos e renda mais elevada. Claramente, trata-se dos profissionais mais experientes, que, por motivos institucionais, tiveram condições de serem locados ou de migrarem para as escolas das áreas com maior renda. Enquanto o perfil puro 3 reúne uma maior proporção de professores da rede municipal, o perfil misto 3 com 1 apresenta uma proporção considerável de professores da rede estadual. As demais características são análogas.

Em síntese, a tipologia oferecida pelo modelo GoM, quando associada a aspectos espaciais e institucionais da política educacional, parece oferecer elementos de grande relevância para o entendimento do processo de implementação das políticas educacionais em São Paulo. Destacam-se, sobretudo, os aspectos que dizem respeito à política de recursos humanos das organizações responsáveis pela implementação da política de ensino fundamental (secretarias Estadual e Municipal de Educação). A seguir, na conclusão, buscamos extrair algumas das principais consequências da análise realizada neste artigo.

\section{CONCLUSÃO}

Os resultados observados até aqui mostram alguns aspectos importantes do processo de implementação da política educacional, aspectos muitas vezes negligenciados pela literatura e pelos formuladores de políticas públicas. Os principais elementos a serem destacados são, em primeiro lugar, as escolhas dos profissionais que efetivamente implementam as políticas de educação ${ }^{11}$. Essas escolhas aparecem em nossos resultados como bastante importantes para o processo de implementação da política, como sugere o argumento original de Lipski (1983). A rigor, do ponto de vista de uma perspectiva puramente individual, é relativamente natural esperar que os profissionais de educação não queiram ensinar nas escolas mais distantes, sobretudo no caso daque- 
les profissionais com jornadas de trabalho maiores. Soma-se a isso o fato de que essas escolas reúnem, muitas vezes, alunos que apresentam acúmulos de desvantagens sociais e econômicas.

Embora existam políticas que tentam enfrentar esse dilema - tal como o chamado adicional por local de exercício existente em escolas estaduais e municipais -, até agora o sistema educacional não foi capaz de produzir incentivos suficientes para reverter tal efeito, como os dados apresentados neste artigo demonstram. Vale notar que, mesmo que essas escolhas sejam legítimas do ponto de vista individual, elas podem acarretar resultados agregados indesejáveis do ponto de vista da política mais geral.

Em segundo lugar, os arranjos institucionais das políticas públicas e, em particular, os sistemas de incentivo associados influenciam as escolhas dos profissionais de educação. Os resultados observados sugerem que os sistemas de incentivo presentemente existentes contribuem para alocar mais frequentemente em áreas com alta concentração de pobreza os profissionais mais descontentes (no sistema municipal) ou os profissionais menos qualificados (no sistema estadual). De fato, a longa ausência de concurso público no sistema estadual contribui para a maior presença de profissionais menos qualificados e com menor experiência profissional, localizados notadamente em escolas de áreas mais pobres. Por outro lado, as regras impessoais de alocação e de promoção de professores concursados contribuem para a maior concentração de profissionais mais experientes e mais bem classificados em escolas de áreas mais ricas da cidade, tanto no sistema municipal quanto no estadual.

Em terceiro lugar, parece claro que a dimensão espacial tende também a condicionar as escolhas dos profissionais de educação e, de forma menos nítida, no caso observado, o próprio processo de implementação. As grandes dificuldades de deslocamento na cidade de São Paulo e, provavelmente, as dificuldades explicitadas por professores nas entrevistas qualitativas de ensinar em escolas localizadas em áreas, por exemplo, com altos índices de violência (Torres et alii, 2008) tendem a impor "custos" monetários e não monetários aos profissionais de educação que têm de se deslocar para lecionar nessas áreas. Esse efeito pode ser mais bem observado entre os profissionais concursados, pois eles têm alguma autonomia na escolha do local de ensino, autonomia proporcionada pelo arranjo institucional da política. 
Em outras palavras, na perspectiva apresentada neste artigo, o espaço importa porque tal dimensão se articula às escolhas dos profissionais de educação e à lógica de implementação da política. Trata-se, a rigor, de uma abordagem bastante distinta de vários estudos contemporâneos da área de segregação que enfatizam o impacto dos fenômenos denominados efeitos de vizinhança (Durlauf, 2001) - isto é, o impacto do processo de influência recíproca entre os alunos (peer group effect) ou a influência dos adultos sobre os mais jovens (role model effect) - como fatores decisivos na explicação de por que as variáveis espaciais acarretam efeitos ${ }^{12}$.

Vale notar, porém, que não é trivial construir um sistema de incentivos adequado, que permita contrabalançar as escolhas dos profissionais de educação quanto aos locais de ensino. Tais dificuldades são significativas sobretudo quando consideramos a rigidez da legislação que rege o magistério. Por exemplo, a implementação de remuneração diferenciada para o exercício profissional em locais "mais indesejáveis" do ponto de vista do professor esbarra em dificuldades de toda ordem relacionadas ao problema da isonomia, à legislação sobre direitos adquiridos e à própria dificuldade de identificar adequadamente esses locais.

Em suma, produzir políticas educacionais homogêneas, em espaços urbanos tão heterogêneos como os existentes no Brasil, é tarefa institucional de grande importância e de grande dificuldade. Tais políticas demandam, provavelmente, a adoção de mudanças significativas na estrutura de incentivos dos profissionais de ensino e, a exemplo do caso uruguaio (Rematoso e Kaztman, 2008), a implementação de escolas diferenciadas nos locais onde o sistema educacional tem mais dificuldade de produzir resultados. Esperamos que este artigo possa contribuir para esse debate.

(Recebido para publicação em fevereiro de 2009)

(Reapresentado em junho de 2009) (Versão definitiva em fevereiro de 2010) 


\section{NOTAS}

1. No original, "street level bureaucracy" (Lipsky, 1983).

2. Menezes Filho e Pazello (2007) sugerem que os salários dos professores não são fatores explicativos relevantes do desempenho escolar, mas não negam a proposição de Hanusheck (1999), de que os professores são importantes no processo educacional.

3. Tais elementos são amplamente evidenciados pelos resultados mais recentes derivados do sistema público de avaliação escolar, como o Ideb (Índice de Desenvolvimento da Educação Básica) e a Prova Brasil.

4. Por estratégias espaciais entendemos a possibilidade de determinado gestor público priorizar, de forma explícita ou implícita, determinadas áreas urbanas. Neste artigo, não aprofundamos a discussão desse tipo de estratégia.

5. A propósito dessa técnica, ver Anselin (1995). O mapa em questão não será aqui apresentado em virtude do espaço. Foi utilizado o método de classificação denominado queen contiguity de primeira ordem.

6. O GoM identifica inicialmente os chamados perfis puros, que são aqueles que mais diferenciam as variáveis em questão. A seguir, destaca os chamados grupos mistos, que agrupam combinações de grupos puros. O número de grupos puros selecionados é de escolha do analista.

7. Os professores pertencentes aos perfis mistos compartilham características de perfis extremos diferentes. De acordo com o critério utilizado neste estudo, os perfis mistos têm predominância de características de um determinado perfil extremo, combinadas, secundariamente, com um conjunto relevante de características de outro perfil extremo (ver Anexo 1).

8. Em relação ao perfil puro 1, o professor com perfil misto 1 com 3 apresenta uma carga horária de trabalho maior (de 40 a 49 horas), tem mais tempo exercendo a profissão (mais de 15 anos), é motivado, não pediria transferência da escola em que trabalha e leva mais tempo para se deslocar até a escola (mais de 15 a 30 minutos). Em termos demográficos, é branco, encontra-se em uma faixa etária mais elevada (mais de 40 a 50 anos) e é casado. Por outro lado, o professor com perfil misto 1 com 2 apresenta uma carga horária de trabalho maior (de 50 horas ou mais), leva mais tempo para se deslocar até a escola em que trabalha (mais de 15 a 30 minutos), tem um rendimento inferior (mais de $\mathrm{R} \$ 2.000$ a $\mathrm{R} \$ 3.000$ ) e trabalha em mais de uma escola.

9. Em comparação ao perfil puro 2, o professor com perfil misto 2 com 3 apresenta uma pontuação no concurso discriminante (sendo a pontuação muito elevada ou elevada), tem um rendimento inferior (mais de $R \$ 2.000$ a $R \$ 4.000$ ) e distingue-se também por aspectos demográficos: o professor desse perfil tem cor da pele branca, amarela e preta. É interessante notar que, nesse caso, a variável motivação não se mostrou discriminante; já no perfil puro 1, o professor apresenta um alto grau de desmotivação. O professor com perfil misto 2 com 1 permanece mais tempo na escola em que trabalha, a variável pontuação no concurso mostrou-se discriminante (sendo a pontuação muito elevada ou elevada), apresenta uma remuneração ligeiramente inferior (mais de $R \$ 3.000$ a $R \$ 4.000$ ) e leva menos tempo para se deslocar até a escola em que trabalha.

10. Em relação ao perfil puro 3, o professor com perfil misto 3 com 2 apresenta tempo de permanência ligeiramente inferior (até 4 horas), tem maior número de faltas (10 ou 


\section{Haroldo da Gama Torres, Sandra Gomes, Thais Pavez e Edgard Fusaro}

mais), é casado e participa do sindicato (é membro da diretoria ou participa ativamente). O professor com perfil misto 3 com 1 apresenta duas diferenças importantes: é da rede estadual e é motivado (sendo que a variável motivação não se mostrou discriminante para o perfil puro). Além disso, possui uma carga horária semanal inferior (até 39 horas), a pontuação no concurso foi intermediária (portanto, inferior à do perfil 3, que se encontra na categoria muito elevada ou elevada), é casado, tem uma remuneração inferior (mais de $\mathrm{R} \$ 4.000$ a $\mathrm{R} \$ 5.000$ ) e a variável tipo de vínculo não se mostrou discriminante.

11. A literatura de política é, em geral, rica em análises que buscam compreender as escolhas dos formuladores de políticas públicas, mas muito mais pobre no entendimento das escolhas dos profissionais do nível da rua que efetivamente implementam tais políticas.

12. Não negamos a existência de tais efeitos, mas ressaltamos a importância dos elementos institucionais.

\section{REFERÊNCIAS BIBLIOGRÁFICAS}

ANSELIN, Luc. (1995), "Local Indicator of Spatial Association - LISA". Geographical Analysis, vol. 27, no 2, pp. 91-115.

BARRET, Susan M. (2004), "Implementation Studies: Time for a Revival? Personal Reflections on 20 Years of Implementation Studies". Public Administration, vol. 82, no 2, pp. 249-262.

BARROS, Ricardo Paes de et alii. (2001), “Determinantes do Desempenho Educacional no Brasil". Textos para Discussão, no 834. Rio de Janeiro, Ipea.

BERKMAN, Lisa, SINGER, Burton e MANTON, Kenneth. (1989), “Black/White Differences in Health Status and Mortality among the Elderly". Demography, vol. 26, no 4, pp. 661-678.

DAVIDSON, Jonathan et alii. (1988), "A Study of Depressive Typologies Using Grade of Membership Analysis". Psychological Medicine, vol. 18, pp. 179-189.

DURLAUF, Steven N. (2001), “The Memberships Theory of Poverty: The Role of Group Affiliations in Determining Socioeconomic Outcomes", in S. H. Danziger e R. H. Haveman (eds.), Understanding Poverty. New York, Russell Sage Foundation, pp. 392-416.

FIGUEIREDO, Argelina et alii. (2005), Relatório final do Projeto BRA/04/052 Rede de Pesquisa e Desenvolvimento de Políticas Públicas: Rede-Ipea II. Mimeo.

GUIMARÃES, Nadya A. e MELO, Frederico L. B. (2008), Quem Recorre a Instituições do Mercado de Trabalho?: Uma Tipologia dos Demandantes a Agências de Emprego em São Paulo. Trabalho apresentado no XVI Encontro Nacional de Estudos Populacionais. Caxambu, Abep. 
HANUSHECK, D. (1999), "Do Higher Salaries Buy Better Teachers?". Working Paper 7.082. National Bureau of Economic Research. Cambridge, MA. Disponível em http:/ / www.nber.org.

HILL, Michael (ed.). (1982), New Agendas in the Study of the Policy Process. Hertfordshire, Harvester Whetsheaf.

HONIG, Meredith I. (ed.). (2006), New Directions in Education Policy Implementation: Confronting the Complexity. Albany, State University of New York Press.

IMMERGUT, Ellen. (1998), "The Theoretical Core of the New Institutionalism". Politics E Society, vol. 26, no 1, pp. 5-34.

LAMB, Vicki L. (1996), “A Cross-National Study of Quality of Life Factors Associated with Patterns of Elderly Disablement". Social Science \& Medicine, vol. 42, no 3, pp. 363-377.

LIPSKY, Michael. (1983), Street-Level Bureaucracy: Dilemmas of the Individual in Public Services. New York, Russell Sage Foundation.

MANTON Kenneth G., WOODBURY, Max A. e TOLLEY, H. Dennis. (1994), Statistical Applications Using Fuzzy Sets. New York, John Wiley and Sons.

MENEZES FILHO, Naércio Aquino e PAZELLO, Elaine. (2007), "Do Teachers Wages Matter for Proficiency? Evidence from a Funding Reform in Brazil". Economics of Education Review, vol. 26, no 6, pp. 660-672.

PETERS, B. Guy. (2005), Institutional Theory in Political Science: The New Institutionalism. New York, Continuum.

PICCINELLI, Marco et alii. (1999), “Typologies of Anxiety, Depression and Somatization Symptoms among Primary Care Attenders with No Formal Mental Disorder". Psychological Medicine, vol. 29, pp. 677-688.

PORTRAIT, France, LINDEBOOM, Maarten e DEEG, Dorly. (2001), “Life Expectancies in Specific Health States: Results from a Joint Model of Health Status and Mortality of Older Persons". Demography, vol. 38, no 4, pp. 525-536.

REMATOSO, Alejandro e KAZTMAN, Ruben. (2008), “Aprendendo Juntos. Desafios na Educação a partir de Processos de Segregação Urbana", in L. C. de Q. Ribeiro e R. Kaztman (orgs.), A Cidade contra A Escola: Segregação Urbana e Desigualdades Educacionais em Grandes Cidades da América Latina. Rio de Janeiro, Letra Capital, pp. 245-279.

ROMÁN, Marcela. (2003), “¿Por Qué los Docentes no Pueden Desarrollar Procesos de Enseñanza-Aprendizaje de Calidad en Contextos Sociales Vulnerables?". Persona y Sociedad, vol. 17, no 1, pp. 113-128.

SOARES, Tufi Machado. (2005), “Modelos de Três Níveis Hierárquicos para a Proficiência dos Alunos de 4a Série Avaliados no Teste de Língua Portuguesa do Simave/Proeb-2002". Revista Brasileira de Educação, no 29, pp. 73-87.

SYDENSTRICKER-NETO, John. (2004), Land-Cover Change and Social Organization in Brazilian Amazonia. Tese de doutorado em Sociologia do Desenvolvimento, Cornell University, Ithaca, New York.

TALBOT, Lisa M. et alii. (1999), “Application of Fuzzy Grade-of-Membership Clustering to Analysis of Remote Sensing Data". Journal of Climate, vol. 12, pp. 200-219. 
TILLY, Charles. (1999), Durable Inequality. Los Angeles, University of California Press.

TORRES, Haroldo da Gama, GOMES, Sandra e FERREIRA, Maria Paula. (2005), “Educação e Segregação Social: Explorando as Relações de Vizinhança”, in E. Marques e H. G. Torres (orgs.), São Paulo: Segregação, Pobreza e Desigualdade. São Paulo, Senac, pp. 123-142.

TORRES, Haroldo da Gama et alii. (2008), “Educação na Periferia de São Paulo: Ou como Pensar as Desigualdades Educacionais?", in L. C. de Q. Ribeiro e R. Kaztman (orgs.), A Cidade contra A Escola: Segregação Urbana e Desigualdades Educacionais em Grandes Cidades da América Latina. Rio de Janeiro, Letra Capital, pp. 59-90.

WEISS, Carol H. (1998), "Have We Learned Anything New about the Use of Evaluation?". American Journal of Evaluation, vol. 19, no 1, pp. 21-33.

WILSON, R. H. (2008), “A Interação da Forma Urbana e a Política Pública: O Caso da Educação Pública”, in L. C. de Q. Ribeiro e R. Kaztman (orgs.), A Cidade contra a Escola: Segregação Urbana" e Desigualdades Educacionais em Grandes Cidades da América Latina. Rio de Janeiro, Letra Capital, pp. 280-308.

WOODBURY, Max A., CLIVE, Jonathan e GARSON JR., Arthur. (1978), "Mathematical Typology: A Grade of Membership Technique for Obtaining Disease Definition". Computers and Biomedical Research, vol. 11, no 3, pp. 277-298.

WOODBURY, Max A. e MANTON, Kenneth G. (1982), “ANew Procedure for Analysis of Medical Classification". Methods of Information in Medicine, vol. 21, pp. 210-220. 


\section{ANEXO 1 Descrição da Metodologia GoM}

Para a construção da tipologia de professores da rede pública de ensino do município de São Paulo, utilizou-se o método grade of membership (GoM), ou grau de pertencimento. O GoM está fundamentado na teoria dos conjuntos nebulosos (fuzzy sets), de acordo com a qual o pertencimento de um elemento a um dado conjunto não é, necessariamente, exclusivo (Manton, Woodbury e Tolley, 1994). O elemento de um conjunto pode pertencer integralmente a ele ou, de outra maneira, pertencer, simultaneamente, com diferentes graus de intensidade, a vários conjuntos. Os conjuntos nebulosos se opõem aos conjuntos bem definidos (crisp sets), nos quais o pertencimento dos elementos a mais de um conjunto não é possível.

Manton, Woodbury e Tolley enunciaram que a cada elemento $i$ de um conjunto nebuloso $k$ corresponde um escore de grau de pertencimento ao conjunto, denotado por $g_{i k}$, que indica a intensidade da participação do elemento ao conjunto. Os escores variam entre 0 (zero), quando o pertencimento é nulo, e 1, quando o pertencimento é total. Em um conjunto bem definido, todos os elementos têm $g_{i k}$ igual a 0 ou 1 . Por outro lado, em um conjunto nebuloso, $g_{i k}$ pode assumir valores intermediários, já que o elemento $i$ não necessariamente pertence integralmente ao conjunto $k$, podendo pertencer parcialmente a um número $\mathrm{K}$ de conjuntos.

O GoM estima simultaneamente as características prováveis dos perfis (a partir das probabilidades de cada resposta em cada variável pertencer a dado perfil) e o grau de "proximidade" de todos os elementos aos perfis. São identificados, entre os elementos do conjunto, dois ou mais perfis bem definidos, chamados de "perfis extremos", aos quais são relacionados os demais elementos por "graus de pertencimento" a partir de seus atributos. A diferença do GoM em relação aos outros métodos é conferida precisamente pela fundamentação da teoria dos conjuntos nebulosos, pois, na tipologia que o GoM estabelece, a participação dos elementos nos perfis extremos é determinada por sua intensidade, e não por sua exclusividade.

Quando determinado elemento tem todas as características de um dado perfil extremo, seu grau de pertencimento a este é de $100 \%$ e de $0 \%$ aos demais perfis extremos. No entanto, há elementos que possuem características de diferentes perfis extremos, situação em que se apro- 
ximarão mais de um perfil do que de outros ou em que terão posição equidistante entre perfis extremos identificados.

O modelo estatístico que aplica a metodologia GoM identifica, a partir dos dados dos elementos, os perfis extremos com base em máxima verossimilhança e obtém, simultaneamente, os graus de pertencimento de cada elemento aos perfis extremos. Para cada elemento do conjunto nebuloso, é determinado um escore de grau de pertencimento $g_{i k}$, que indica o grau de pertencimento do elemento $i$ ao perfil $k$, isto é, a intensidade de sua "filiação" ao perfil extremo $k$.

Duas condições regem o pertencimento dos elementos aos perfis. De acordo com a primeira delas, o pertencimento de $i$ ao perfil $k$ é de no mínimo zero, não existindo, portanto, pertencimento negativo. Ademais, a soma da intensidade, ou da proporção, da participação de $i$ no total $\mathrm{K}$ de perfis deve ser igual a 1. Matematicamente:

I)

$g_{i k} \geq 0$ para cada $i$ e $k$.

$\sum_{k=1}^{K} g_{i k}=1$ para cada $i$.

Além disso, entende-se que, dentro do conjunto L de respostas possíveis para a questão $j$, a probabilidade de escolha da categoria $l$ pelo indivíduo que pertence integralmente ao perfil extremo $k$ é dada por $\lambda_{k i l}$. Em sua formulação matemática, a segunda condição se apresenta como se segue:

II)

$\lambda_{k j l} \geq 0$ para cada $k, j, i$.

$\sum_{l=1}^{L_{j}} \lambda_{k j l}=1$ para cada $k$ e $j$.

Conforme já mencionado, nem todos os indivíduos têm pertencimento total aos perfis extremos, e, por tal razão, outro pressuposto de entendimento do modelo é que a probabilidade de escolha da categoria $l$ pelo indivíduo $i$ está condicionada a seu escore de grau de pertencimento a $k, g_{i k}$ : 
$\operatorname{Pr}\left(Y_{i j l}=1\right)=\sum_{k=1}^{K} g_{i k} \lambda_{k j l}$

Entendidas as condições e os pressupostos do modelo, sua função de máxima verossimilhança é estabelecida como se segue:

$$
L(y)=\prod_{i}^{I} \prod_{j}^{I} \prod_{l}^{L_{j}}\left(\sum_{k=1}^{k} g_{i k} \lambda_{k j l}\right)^{y_{i j l}} Y^{Y_{i j l}}
$$

Em que:

$I$ = número de elementos da amostra;

$J$ = número de questões;

$L_{j}=$ número de categorias de respostas possíveis para J;

$K=$ número de perfis de referência.

O GoM é flexível o suficiente para, dentro dos parâmetros colocados pela reflexão teórica sobre o tema, permitir o teste de várias alternativas para a obtenção dos perfis extremos, inclusive quanto ao número deles, e para auxiliar na escolha do mais adequado. Onúmero de perfis a serem obtidos no final da investigação depende, em última instância, dos objetivos da análise, da capacidade, dos conhecimentos e da decisão do pesquisador. Uma vez que os perfis extremos são delineados tendo em vista a contribuição de cada categoria de resposta e de cada variável para a descrição do perfil, quanto maior o número de variáveis utilizadas na construção da tipologia, mais robusta a descrição realizada. Essa característica do método foi uma das razões pelas quais este estudo utilizou o GoM em detrimento de outros métodos.

A análise a seguir é fundamentada nos dados do survey com professores da rede pública de ensino do município de São Paulo, realizado pelo CEM-Cebrap em junho de 2007. As variáveis consideradas na análise foram: tempo de permanência em sala de aula; carga horária semanal em todos os trabalhos; escolaridade; classificação no último concurso; motivação quanto ao trabalho na escola atual; desejo de transferência de escola; número de faltas em 2006; tempo de deslocamento até o trabalho; principal meio de transporte utilizado para trabalhar; renda familiar; cor/raça; faixa etária; estado civil; tipo de escola em que trabalha; trabalho adicional em outra escola; envolvimento 
com o Sindicato dos Professores; tempo de trabalho na escola atual; tempo de trabalho como professor da rede pública; tipo de vínculo de trabalho.

Como o GoM utiliza, exclusivamente, variáveis categóricas, as variáveis contínuas foram categorizadas levando-se em consideração a distribuição empírica de cada uma delas e, ao mesmo tempo, sua interpretação. $\mathrm{O}$ Anexo 2 apresenta a descrição das variáveis consideradas neste estudo, com as respectivas categorias consideradas para cada uma delas. 
Perfis do Professorado da Rede Pública de São Paulo: A Interação entre Espaço...

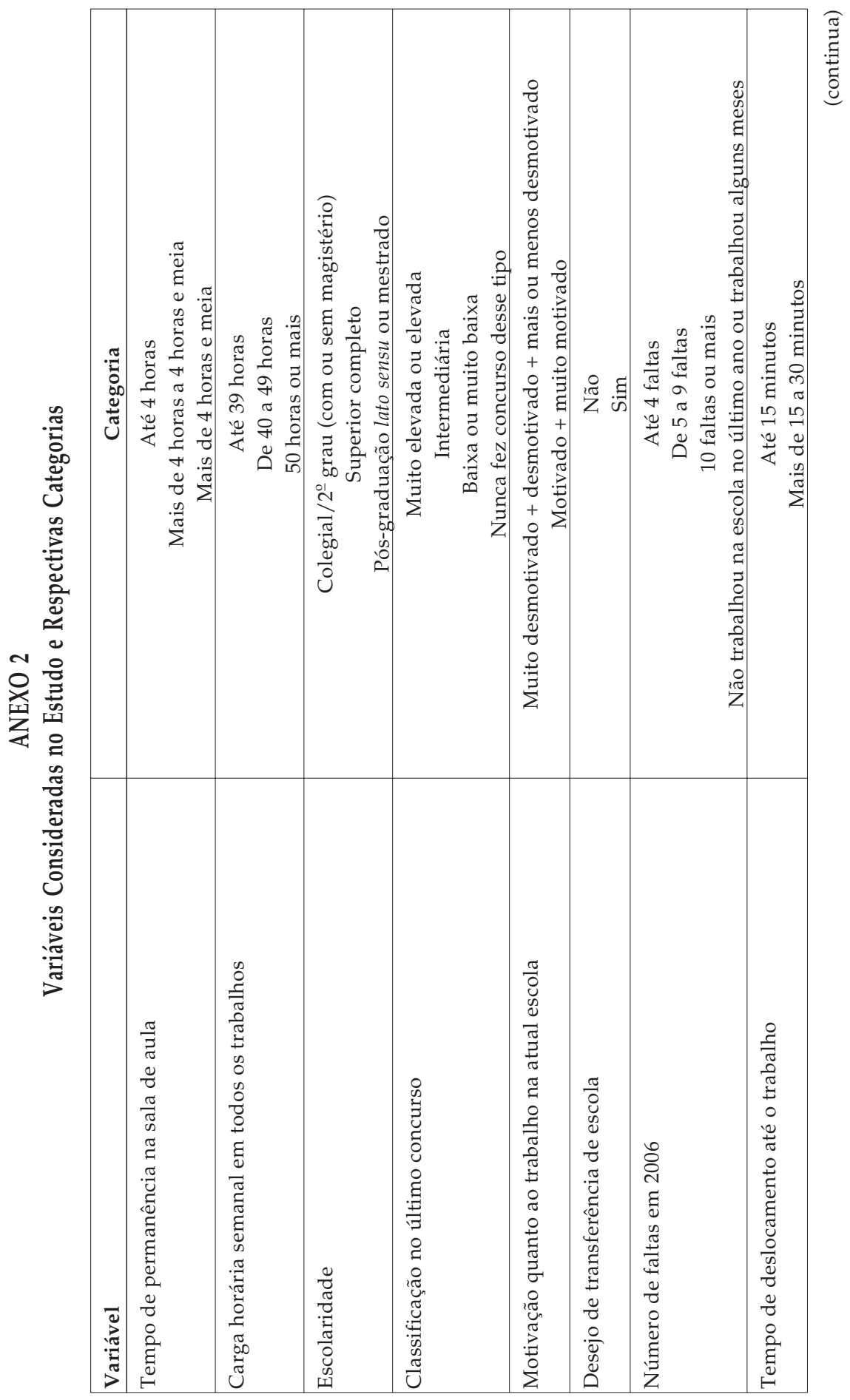


Haroldo da Gama Torres, Sandra Gomes, Thais Pavez e Edgard Fusaro

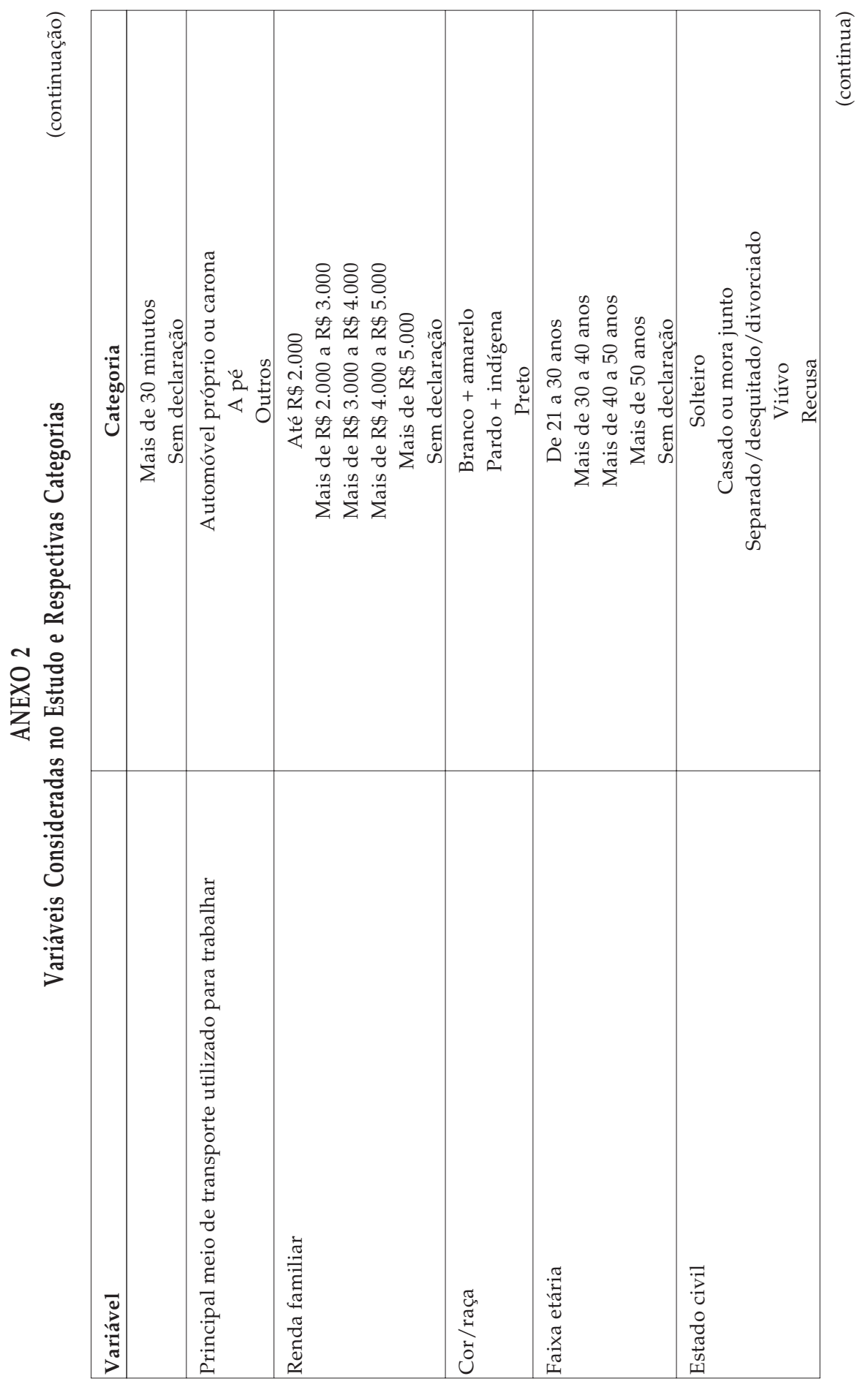


Perfis do Professorado da Rede Pública de São Paulo: A Interação entre Espaço...

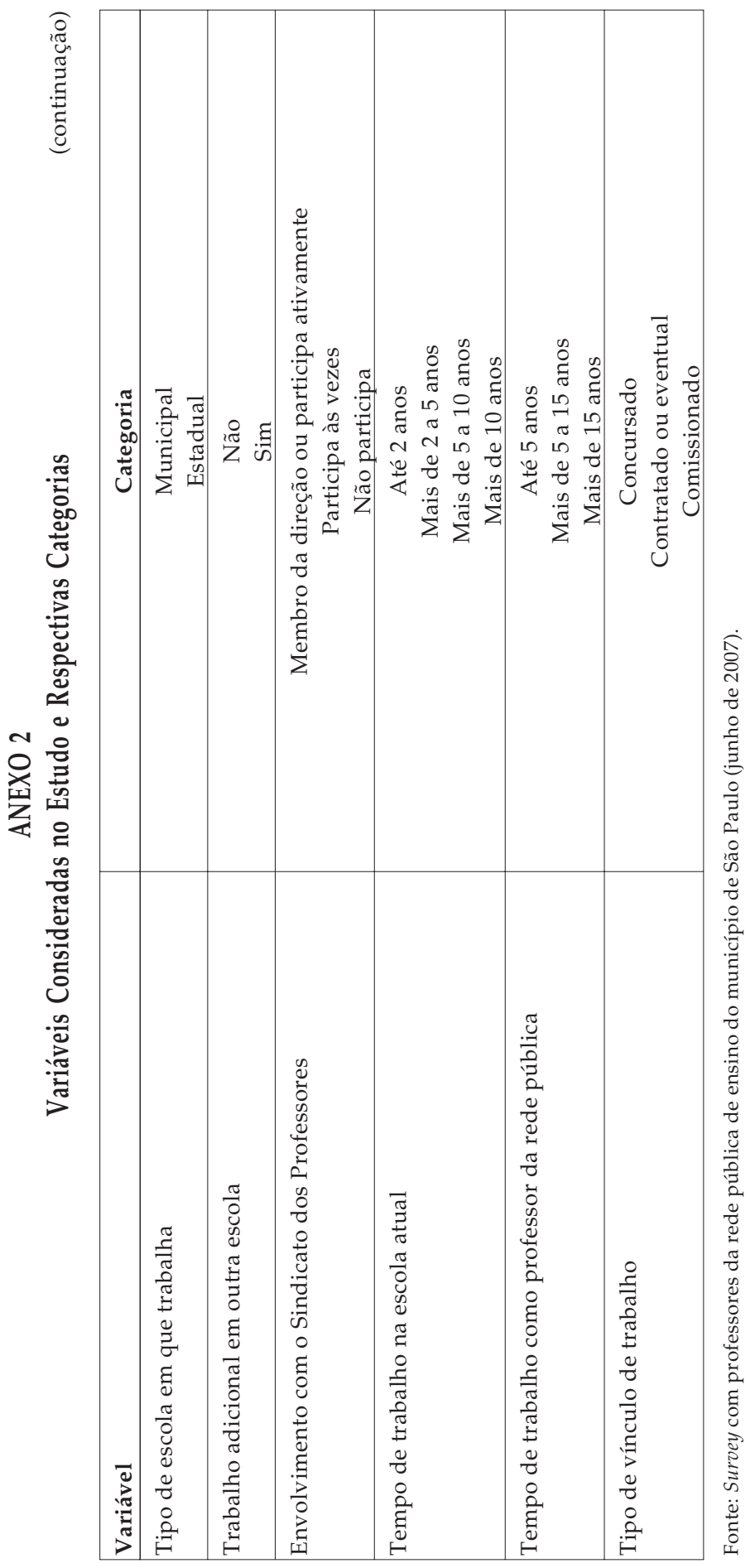




\author{
ABSTRACT \\ Profiles of Public Schoolteachers in São Paulo, Brazil: The Interaction \\ between Space, Institutional Rules, and Individual Choices in Public \\ Policy Outcome
}

Unlike classical public policy analyses that emphasize the policymakers' role, this article argues that the choices by professionals that directly implement policies inside primary schools have a significant impact on their outcome. The analysis is based on a survey of 800 State and Municipal first-to-fourth-grade schoolteachers in São Paulo and was based on a typology of teachers using the "grade of membership" (GoM) technique. This analysis showed that the types of teachers are allocated differently according to the school system (State versus Municipal) and school locations (poor versus non-poor neighborhoods).

Key words: implementation; social policies; education; segmentation; São Paulo

\title{
RÉSUMÉ
}

Profils des Enseignants de l'École Publique à São Paulo: Interaction entre Espace, Règles Institutionnelles et Choix Individuels dans les Résultats d'une Politique Publique

Contrairement aux analyses classiques des politiques publiques qui soulignent le rôle de leurs auteurs, dans cet article on cherche à montrer que les choix des responsables directs de la mise en place de la politique de l'enseignement fondamental se répercutent significativement sur l'impact de ces politiques. Cette analyse, dont le point de départ est un survey réalisé auprès de 800 professeurs des écoles de l'État et de la municipalité de São Paulo, de la première à la quatrième année de l'enseignement fondamental, a été organisée selon l'établissement d'une typologie des enseignants par le moyen de la technique de "grade of membership" (GoM). L'analyse a montré que les types d'enseignants en poste diffèrent selon les réseaux d'enseignement et selon l'emplacement de l'école (en zone de pauvreté ou non).

Mots-clé: mise en place; politiques sociales; éducation; segmentation; São Paulo 